\title{
UM BONDE CHAMADO CONSUMO, UM OBJETO CHAMADO DESEJO
}

Maria Luiza Zenobio de Assumpção Villar Laufhütte ${ }^{1}$ (Lully Villar)

Pontifícia Universidade Católica do Rio de Janeiro - PUC-Rio

lullyvillar@hotmail.com

Alberto Cipiniuk

Pontifícia Universidade Católica do Rio de Janeiro - PUC-Rio

acipiniuk@gmail.com

Resumo: O foco de interesse deste artigo é o Campo do Design inserido no Campo do Cinema e sua intervenção na produção de objetos cenográficos para filmes de Hollywood que, posteriormente, são desejados pelos consumidores. O tênis Nike Air Mag, por exemplo, usado pelo personagem Marty McFly interpretado por Michael J. Fox no filme De volta para o futuro $I^{2}$, criou uma espécie de contagem regressiva por parte dos espectadores para o seu lançamento. Em 2011, a Nike o lançou no mercado em um número limitado de apenas mil e quinhentas unidades em um leilão virtual cujo lance inicial era de cinco mil e quinhentos dólares. Todos os pares foram vendidos rapidamente. Nosso objetivo é compreender o consumo destes objetos com base na teoria das trocas simbólicas desenvolvida por Pierre Bourdieu.

Palavras-chave: design, objetos cenográficos, desejo, consumo, Pierre Bourdieu

\begin{abstract}
The focus of this paper is the Field of Design inserted in the Field of Cinema and its intervention in production of props for Hollywood movies which subsequently are desired by consumers. The Nike Air Mag shoes, for example, used by the character Marty McFly played by Michael J. Fox in the movie Back to the Future II, created a kind of countdown by the spectators for its launch. In 2011, Nike launched it on the market in a limited number of only fifteen hundred units in a virtual auction whose starting bid was five and a half thousand dollars. All pairs were sold quickly. Our goal is to understand the consumption of these props based on the theory of symbolic exchanges developed by Pierre Bourdieu.
\end{abstract}

Keywords: design, props, desire, consumption, Pierre Bourdieu

\footnotetext{
${ }^{1}$ Bolsista CNPQ.

${ }^{2}$ De volta para o futuro II. Titulo original: Back to the future part II. Estados Unidos, 1989. Cor. 108 min. Direção: Robert Zemeckis.
} 


\section{INTRODUÇÃO}

De acordo com a vertente teórica que empregamos à nossa pesquisa e a este artigo, o Campo do Design ${ }^{3}$ inicia a sua constituição a datar da segunda metade do século XVIII, mais precisamente a partir da Revolução Industrial, a qual ofereceu as condições de possibilidade para o desenvolvimento de um novo campo de atividade profissional para um conjunto de novidades tecnológicas, assim como para as novas necessidades sociais que surgiram ao longo deste período histórico, tal como descreveu Adrian Forty (2007, p. 22) no livro Objetos de desejo. ${ }^{4}$

Forty $(2007$, p. 12) relatou que, em relação aos artefatos industriais, a palavra design poderia assumir dois significados principais. $O$ primeiro se referiu à aparência ou à forma dos objetos que era determinada sob julgamentos relacionados às noções de beleza. O segundo sentido foi relacionado à preparação de instruções de racionalização para a produção de bens manufaturados, isto é, o primeiro se reportava à dimensão estética e o segundo à dimensão utilitária do objeto industrial. De acordo com esses sentidos ou significados, fica claro que seria um enorme desacerto desmembrá-las, pois a palavra design manifesta, em um sentido mais amplo, que a aparência dos objetos é uma consequência das condições de sua produção, ou seja, que a sua dimensão material não pode ser apartada da sua dimensão simbólica. Não se trata, portanto, de opor uma e outra, mas de entendê-las como complementares.

Paralelamente, um dos aspectos importantes trazidos por Forty em Objetos de desejo, foi a situação histórica onde o fenômeno design ocorreu pela primeira vez, pois estabelecendo-o como parte integrante do sistema de produção de bens manufaturados originário do sistema capitalista, ficava subentendido que a fabricação de objetos industriais visava o lucro para o fabricante e que o design não possuía unicamente o objetivo de torná-los belos ou funcionais, mas também a produção de mais valia. Forty ressaltou que isso que é o design, portanto, é uma prática social encarregada de criar ou produzir os objetos, principalmente, industriais e também o próprio "desejo" de consumo por tais objetos. Aliás, esse é o título do livro de Forty que, de modo geral, nos perguntou: quem de fato produz o desejo por esse ou por aquele objeto? Essa noção se verificou importantíssima para a abordagem sobre o design, pois ficou claro que o modo de produção industrial constrói não apenas o objeto em si mesmo, mas também o desejo da sua aquisição - a sua necessidade -, assim como outras noções simbólicas que o cercam.

Por noções simbólicas entendam-se os processos empregados pelos designers para conquistar o público consumidor por algo ou alguma coisa que tenha ou não tenha valor de uso. Tal como, por exemplo, a importante contribuição do design para a construção e legitimação de valor social abstrato, como foi o caso da extrema limpeza (FORTY, 2007, p. 215). Essa noção foi construída ou produzida ao mesmo tempo que certos objetos industriais atinentes à higiene pessoal das pessoas e talvez este seja o mais importante conteúdo do livro Objetos de desejo para pensar o Campo do Design. Aspiradores de pó com formas camaleônicas, por exemplo, foram produzidos em profusão a partir de 1920 logo que a indústrias percebeu que os mesmos poderiam ser

\footnotetext{
${ }^{3}$ Campo do Design, Campo do Cinema ou Campo do Teatro são termos técnicos formulados por Pierre Bourdieu (1983, p. 44 -45) e por essa razão grafados em letra maiúscula.

${ }^{4}$ FORTY, Adrian. Objetos de desejo. São Paulo: Cosac Naify, 2007.
} 
os maiores adversários contra o que as pessoas denominavam ser a sujeira. 0 aspirador além de importante é emblemático, pois um arbitrário cultural abstrato, tal como a "limpeza" ou a "higiene" se concretiza em um objeto industrial que se apresenta como uma ferramenta para "eliminar" ou sugar para o seu interior a "sujeira" de algum lugar julgado "sujo". Ademais e muito a propósito, a organização (racionalização ou ordenação dos espaços) e a higiene eram consideradas as origens da beleza. Assim, podemos observar que a exaltação à higiene era propagada com extremada força pelo mercado, isto é, pelos produtores industriais de aspiradores de pó e, consequentemente, as donas-de-casa passaram a considerar que era de suma importância não permitirem que o pó se acumulasse. A noção demonizada do pó acumulado era uma noção simbólica produzida pelo próprio mercado produtor de produtos de higiene, incluindo o aspirador de pó. Conforme sublinhado por Forty (2007, p. 20), a ascensão do capitalismo está incontornavelmente ligada não apenas à produção de objetos industriais, mas à capacidade de "inovar" e vender os produtos. Aliás, inovar, ou o conceito da produção do "novo" com fins comerciais, foi também um produto ou uma tecnologia social produzida pela Revolução Industrial para legitimar a produção de valores ou transformar os antigos valores simbólicos naqueles que interessavam à produção da mais valia. Assim, o design precisa ser compreendido de forma mais ampla, não apenas restrito aos aspectos objetivos do produto, isto é, técnicos, mas também em relação à produção das noções simbólicas que ajudavam-no a construí-lo, pois elas alteraram substancialmente a forma como percebemos as mercadorias. Há algo muito além da função e da finalidade utilitária dos objetos industriais a ser investigado. Ou seja, o valor de uso pode ser examinado a partir de seus significados, suas funções e seus aspectos visuais.

Com o tempo, as casas passaram a ser preenchidas com os objetos industriais que, atualmente, são vendidos aos milhares diariamente. Os teóricos do Campo do Design observaram que os objetos constituem o entorno e o ambiente próprio de cada indivíduo. No último parágrafo de Objetos de desejo, Forty (2007, p. 330) escreveu: "Este livro [...] pretendeu mostrar os modos pelos quais o design transforma ideias sobre o mundo e relações sociais na forma dos objetos". Torna-se óbvio que o design não pode ser compreendido como algo independente, algo em si mesmo, mas sim como uma prática social que foi realizada para atender a demandas sociais. Trata-se de uma forma de trabalho, de produção de objetos inserida na sociedade industrial capitalista. Ao entendermos o fenômeno design revelador do sistema econômico da sociedade industrial, concluímos que o mesmo é também determinado por valores culturais que se emulam a esse modo de produção. Ao mesmo tempo, a demanda do fenômeno design pode ser entendida como uma prática social que produz peças que operam como um código de distinção social de diferentes grupos da sociedade.

Observamos que, conforme explicou Gustavo Bomfim ${ }^{5}$ (2014, p. 23-24), o design traduz-se em uma atividade representativa tanto dos objetos de uso como de sistemas de informação materializando, através dos mesmos, os ideais, os arquétipos, as conviç̧ões e também as contradições e as incoerências de uma sociedade, incorporando uma porção dos valores e manifestações culturais que a compõe.

\footnotetext{
${ }^{5}$ BOMFIM, Gustavo Amarante. Coordenadas cronológicas e cosmológicas como espaço das transformações formais. In: COUTO, Rita Maria de Souza; OLIVEIRA, Alfredo Jefferson de; FARBIARZ, Jaqueline Lima; NOVAES, Luiza (org.). Formas do design: por uma metodologia interdisciplinar. Rio de Janeiro: Rio Books, 2014.
} 
Ademais, o design é componente da criação cultural de uma sociedade e, como tal, é também uma prática social dessa mesma sociedade, expressando ou mesmo denunciando suas perfeições ou imperfeições.

A sociedade de consumo evidencia-se primeiramente pelo desejo socialmente construído da posse do que excede o necessário e é frívolo ou mesmo considerado uma mercadoria de luxo. A constante insaciabilidade pela aquisição de algo "novo" que é preliminarmente satisfeita logo gera outra necessidade como algo automático que se insere em um ciclo inesgotável de consumo.

Se desenvolvida especialmente com a Revolução Industrial, a sociedade de consumo ganha agilidade maior ao longo da segunda metade do século $\mathrm{XX}$, quando consumir passa a significar o desenvolvimento econômico e elemento de mediação das variadas relações que se estabelecem nas sociedades.

Percebemos que os objetos tornaram-se integrantes das nossas atividades frequentes. Na prática do consumo, baseiam-se as novas relações estabelecidas entre os objetos e os sujeitos sociais, nas quais a importância dos objetos é cada vez mais valorizada pelas pessoas. Desenvolveu-se uma enorme gama de objetos disponibilizada ao consumidor, extrapolando as necessidades cabais de compra. $\mathrm{Na}$ verdade, verifica-se que não existe mais a perspectiva do simples ato de comprar um objeto somente pela sua finalidade de uso sem a possibilidade do poder de escolha do mesmo. Em vista disso, a eleição de determinado objeto torna-se significativa, pois a escolha personaliza o proprietário do mesmo. Tal indivíduo insere-se, sobretudo, em um grupo de determinada ordem econômica, unindo-se aos seus semelhantes e diferenciando-se das demais classes sociais.

As mercadorias estabelecem o fundamento da existência do consumo, constituindo infinitas criações que logo serão destruídas e substituídas, assim como o desejo por esta ou aquela mercadoria. Todavia, por qual motivo as pessoas passaram a desejar para si mesmas um objeto que está em um filme? Consideramos necessário para esse artigo o entendimento do design de produção do filme para o desenvolvimento dessa complicada demanda social. Encontram-se objetos de diversos filmes hollywoodianos à venda em leilões físicos ou virtuais, galerias, lojas e até mesmo em museus americanos. O objetivo do nosso artigo é compreender o consumo destes objetos com base na teoria das trocas simbólicas desenvolvida por Pierre Bourdieu.

Entre carros que voam e outras maravilhas do ano de 2015 retratado no filme De volta para o futuro II realizado em 1989, um dos itens criou uma espécie de contagem regressiva por parte dos espectadores para o seu lançamento até tal ano de fato. 0 tênis Nike Air Mag usado pelo personagem Marty McFly, interpretado por Michael J. Fox, além de aparentemente confortável, ajustava-se automaticamente aos pés. Antes do esperado, em 2011, a Nike o lançou no mercado. Mesmo não possuindo a tal tecnologia do ajuste automático, o item foi lançado em um número limitado de apenas mil e quinhentas unidades em um leilão virtual cujo lance inicial era de cinco mil e quinhentos dólares. ${ }^{6}$

As práticas de consumo ocorrem dentro de um campo ou universo simbólico. A partir de Pierre Bourdieu, a noção de campo pode ser identificada como, por exemplo, no Campo da Literatura ou no Campo da Moda e, portanto, julgamos que pode ser

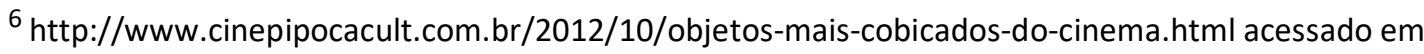
20/04/2016.
} 
empregada também para a indústria cinematográfica. Tratando-se deste artigo, nosso foco de interesse é o Campo do Design inserido no Campo do Cinema e sua intervenção na produção de objetos cenográficos que, posteriormente, são desejados pelos consumidores.

Objetos atuam como mediadores das próprias relações humanas, ou ainda, como intermediários entre o homem, suas vontades e seus desejos. E é nessa medida que abordaremos as relações entre os consumidores e alguns objetos cênicos dos filmes de Hollywood.

\section{DESENVOLVIMENTO}

Até a primeira metade do século $X X$, nos créditos de produções hollywoodianas especialmente, o trabalho de Production Design/Design de Produção era chamado de Art Direction/Direção de Arte. ${ }^{7}$ Todavia, tais produções e até mesmo produções independentes americanas apresentam hoje o crédito de Production Design/Design de Produção o qual refere-se ao projeto ou a eleição de ambientes, móveis e objetos de cena de um filme. O design de produção abarca portanto, além de cenografia (incluindo mobiliário e objetos), o figurino, a maquiagem e os efeitos especiais, quando houver. No âmbito deste artigo, a intenção é abordar tanto objetos de cena como objetos e figurinos utilizados pelos atores.

Vera Hamburger ${ }^{8}(2014$, p. 46) descreveu que são denominados props ou "objetos de contrarregragem" os elementos fundamentais ao desenrolar da ação e também aos objetos de uso pessoal dos personagens e da figuração, como uma mala de viagem e uma agenda, por exemplo.

O trabalho do designer de produção ultrapassa a função de ser um mero intérprete do diretor do filme. Vincent Lobrutto $^{9}(2002$, p. 1) relatou que o processo e aplicação do design de produção apresenta o roteiro com referências visuais, paleta de cores, opções de texturas, detalhes arquitetônicos e de época, escolha de mobiliário e objetos. O designer de produção cria um conjunto visual coeso que apóia a história e que pretende se comunicar diretamente com o espectador.

Ward Preston ${ }^{10}(1994$, p. 75$)$ relata que o designer de produção possui as ferramentas visuais para induzir emoções e é sua a capacidade de manipular associações visuais que definem o estilo de um filme bem projetado. Nós concordamos.

Com o cabelo puxado para trás e trajando um vestido preto, a personagem de Holly Golightly do filme Bonequinha de luxo ${ }^{11}$, interpretada por Audrey Hepburn, desfilava pelas ruas de Nova lorque portando uma piteira e elegantes óculos escuros. ${ }^{12}$

\footnotetext{
7 Observamos que o crédito de Direção de Arte muitas vezes aparece na atualidade como uma função subordinada ao Design de Produção.

8 HAMBURGER, Vera. Arte em cena: a direção de arte no cinema brasileiro. São Paulo: Senac-Sesc, 2014.

9 LOBRUTTO, Vincent. The filmmaker's guide to production design. New York: Allworth Press, 2002.

10 PRESTON, Ward. What an Art Director does: an introduction to Motion Picture Production Design. Los Angeles: Silman-James Press, 1994.

${ }^{11}$ Bonequinha de luxo. Titulo original: Breakfast at Tiffany's. Estados Unidos, 1961. Cor. 115 min. Direção: Blake Edwards.

12 Não é possível deixarmos de julgar curioso por qual motivo os óculos são considerados "elegantes".
} 
O filme não somente foi um sucesso de Hollywood como também ocasionou na popularização do modelo dos óculos Ray Ban Wayfarer quando este ainda não era muito conhecido. O fato mais curioso é que os óculos utilizados por Holly Golightly não eram do modelo Wayfarer nem mesmo da marca Ray Ban. Oliver Goldsmith reeditou seus lendários óculos de sol modelo Manhattan, o qual foi utilizado pela personagem. De qualquer forma, os óculos, assim como a própria Holly, sintetizam o arbitrário cultural disso que passou a ser considerado elegante. Serão esses fatores constituintes do desejo de consumo de tal objeto? Feito à mão na Itália, o Manhattan está até hoje no mercado incluindo a assinatura Dark Tortoiseshell, modelo idêntico ao usado no filme à venda por quatrocentos e quarenta dólares. ${ }^{13}$

A jaqueta preta de couro utilizada por Johnny Strabler, personagem interpretado por Marlon Brando no filme $O$ Selvagem ${ }^{14}$, tornou-se símbolo de uma geração. Oficialmente conhecida como Perfecto, a jaqueta foi utilizada como peça de roupa por James Dean e, posteriormente, por Bruce Springsteen. Seu fabricante original foi a Schott, situada em Nova lorque, sendo a primeira empresa a aplicar zíperes em jaquetas e vendendo-as atualmente por um valor entre quinhentos e novecentos dólares. ${ }^{15}$

Desde 2001, a loja virtual Premiere Props ${ }^{16}$, com o slogan "Bring Hollywood Home" ${ }^{17}$, vende inúmeros objetos e trajes cênicos. Semanalmente, a loja faz leilões virtuais e cada item inclui um certificado de autenticidade para garantir sua integridade. A loja tem parceria com vários estúdios de cinema, tais como Paramount Pictures, Miramax, MGM, DreamWorks, 20th Century Fox e Universal, e os principais independentes, como a Lakeshore Entertainment, Alcon Entertainment, Spyglass, Constantin Film, entre outros.

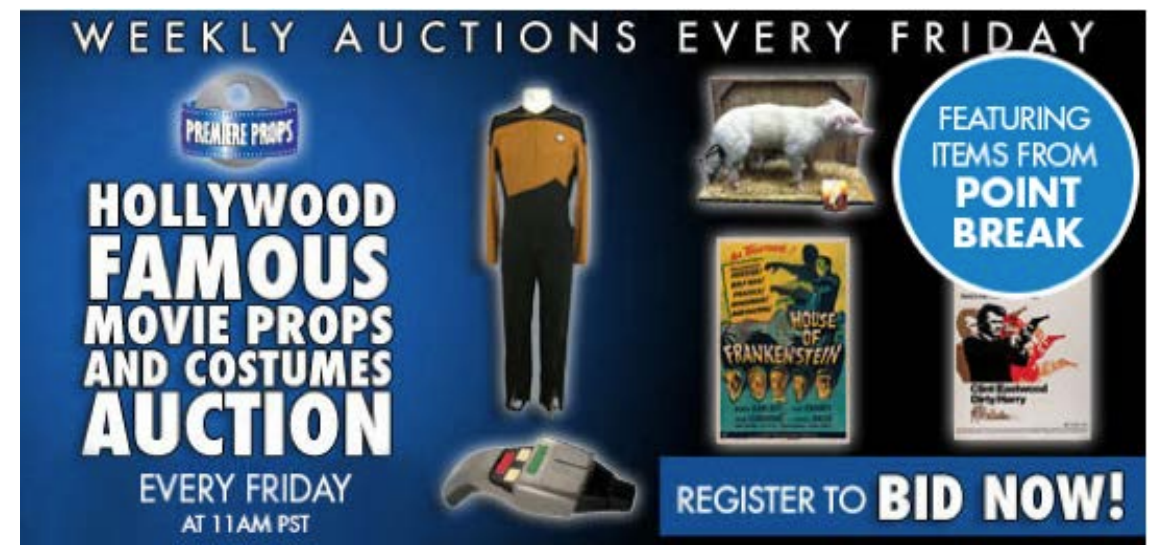

Figura 1 - Anúncio dos leilões semanais no site da Premiere Props

Fonte: http://www.premiereprops.com

\footnotetext{
13 http://www.eyegoodies.com/Oliver-Goldsmith-c-372.html acessado em 20/04/2016.

14 O Selvagem. Titulo original: The wild one. Estados Unidos, 1953. Preto e branco. 19 min. Direção: Laszlo Benedek.

15 https://www.schottnyc.com/search.cfm?searchterm=perfecto acessado em 20/04/2016.

16 http://www.premiereprops.com acessado em 20/04/2016.

17 "Traga Hollywood para casa”.
} 
No interior do The Forum Shops localizado no hotel e cassino Caesars Palace na cidade de Las Vegas, situa-se a loja Antiquities ${ }^{18}$ que vende, entre seus diversos artigos, objetos e trajes cênicos de filmes de Hollywood assinados por algum diretor, ator ou até mesmo por todo o elenco. A jaqueta utilizada em Rocky $\|{ }^{19}$ e assinada por Sylvester Stallone, por exemplo, está à venda por quatro mil novecentos e noventa e cinco dólares. ${ }^{20}$

Entre lojas e leilões, sejam itens fabricados em série ou peças exclusivas, espalhou-se o consumo por objetos cênicos pela sociedade capitalista americana. 0 que temos aqui então? Em conformidade com a orientação teórica por nós utilizada, consideramos que imprimimos projetivamente aos objetos determinados significados através do seu uso social, aquilo que já está legitimado pelo habitus.

Partimos do princípio de que alguns dos aspectos da proposta de Pierre Bourdieu, como, por exemplo, a noção de habitus, são apropriáveis no que diz respeito ao consumo. Este seria, segundo nosso ponto de vista, um sistema de representação simbólico no qual estão plenamente diluídas relações de poder e distinção.

Reexaminando os fundamentos da sociologia, Bourdieu objetivou debater as relações de poder e, por conseguinte, também de dominação existentes em suas suposições teóricas acerca de estruturas sociais, concebendo certas noções, sendo as mais relevantes as noções de "habitus" e "campo". Consideramos que tais noções são fundamentais para o conhecimento e entendimento da investigação realizada por Bourdieu e por vezes articulam-se juntas ou separadas.

Bourdieu retomou a noção de habitus, esta originada na escolástica medieval, e a desenvolveu como uma organização de disposições nas nossas formas de pensar, sentir e agir. Ele (1983, p. 61) explicou que o termo "disposição" parece especialmente adequado para expressar com efeito a noção de habitus, compreendida como "sistema de disposições", pois expressa, primeiramente, a consequência de uma ação organizadora, expondo assim um sentido aproximado ao de palavras como estrutura, por exemplo. Sob outra perspectiva, o termo indica "uma maneira de ser, um estado habitual (em particular do corpo) e, em particular, uma predisposição, uma tendência, uma propensão ou uma inclinação" (BOURDIEU, 1983, p. 61).

Tais disposições ou habitus são socialmente estruturadas e mentalmente estruturantes para cada sujeito que compõe uma sociedade específica. Foram elas analisadas por Bourdieu como flexíveis, ou seja, condicionáveis às estruturas sociais, isto é, estão situadas no tempo e no espaço, tornando-se dinâmicas. Desta forma, o que serve como exemplo em um determinado lugar não serve para outro. O habitus se parece com algo crônico e enraizado no nosso dia a dia, que emerge aleatoriamente em nossas ações e em comportamentos que não percebemos racionalmente. Pensamos antes de agir ou simplesmente agimos? Trata-se de um processo, supostamente, "natural" do qual muitas vezes não temos mais consciência e nos parece rotineiro na nossa existência. Simplesmente o reproduzimos.

Bourdieu (1983, p. 76) explicou que o habitus produz práticas tanto individuais quanto coletivas. É criado um sistema de disposições e um discurso coeso apto a proporcionar e assegurar o domínio simbólico dos princípios praticados pelos

18 http://www.antiquitieslv.com acessado em 20/04/2106.

19 Rocky II. Estados Unidos, 1979. Cor. 119 min. Direção: Sylvester Stallone.

20 http://www.antiquitieslv.com/rocky-ii-sylvester-stallone-signed-jacket/ acessado em 20/04/2106. 
dominados de cada classe social e tal discurso é também observado nos filmes hollywoodianos que produzem a sensação de que objetos são necessários socialmente através da afirmação do seu valor simbólico. Deste modo, os objetos referentes aos personagens que possuem o objetivo de sintetizar o entendimento daquilo que é elegante, chique, bonito ou feio, por exemplo, está inserido na mesma estrutura social de quem os projetou, os próprios designers de produção. Bourdieu observou que pertencemos às estruturas sociais, ou seja, somos todos agentes destas estruturas. Desta forma, passamos a considerar que o uso dos óculos iguais aos de Holly Golightly nos torna elegantes.

O habitus reproduz as práticas peculiares de uma determinada classe ${ }^{21}$ da estrutura social, criando códigos particulares a esta classe específica e concebendo uma lógica para os comportamentos sociais como, por exemplo, a maneira tal qual nos comportamos em determinada cerimônia ou os nossos modos à mesa ou mesmo em relação às nossas operações mentais e intelectuais e todas as práticas que nos cercam o tempo todo, simplesmente, através das ações. Nas primeiras décadas do século XX, milhares de mulheres iam ao cinema, pelo menos, duas vezes por semana, fato comum entre as que pertenciam à mesma classe social e que copiavam os modelos das roupas e penteados das estrelas de Hollywood, descreveu Anne Massey (2000, p. 11) autora de Hollywood beyond the screen: design and material culture ${ }^{22}$. Massey (2000, p. 11) relatou ainda que suas avós compartilhavam do mesmo fascínio pelos filmes de Hollywood e que uma delas teve o objetivo de se parecer com Clara Bow durante os anos de 1920 e com Olivia de Havilland nos anos de 1930. Assim sendo, ambas estavam inseridas no mesmo habitus. Diversos espectadores foram e são agentes das estruturas sociais, representantes do poder de Hollywood sobre o comportamento e os valores dentro de tais estruturas.

Por Bourdieu (1983, p. 44-45), a noção de campo apresentada é esclarecida tal qual um espaço de conflito estruturado por dominantes e também por dominados, cuja estrutura é fortalecida pelos próprios agentes participantes e ativos na mesma. 0 campo não deve ser compreendido tal qual uma estrutura fixa. Os interesses específicos demarcam o conjunto, como os de ordem econômica por exemplo, dos agentes que são possuidores do mesmo habitus. O habitus é estruturado pelo campo e o campo é constituído pelo habitus, ou seja, ele é estruturado e estruturante ao mesmo tempo. O que é copiado dos filmes de Hollywood pelos espectadores já foi legitimado ou consagrado anteriormente pelos agentes de circulação através do próprio habitus coletivo americano. Ou será que tal habitus é influenciado pela prévia validação daquilo que é "elegante" em Hollywood?

Antes de avançarmos, faz-se essencial o entendimento da posição dos agentes dentro do campo, pois o funcionamento do mesmo está delimitado à dominação dos participantes que determinam o que está dentro e aquilo que "deve" ficar fora do campo. O que seria isso que demarca o monopólio da autoridade destes agentes para afirmar que isso é design e aquilo não é? O campo é consequência do sistema de categorização agenciado por estes indivíduos que ao mesmo tempo que atuam, são

\footnotetext{
${ }^{21}$ Observamos que, na realidade, Bourdieu prefere utilizar o termo "lugar social", ao invés de "classe social". Ele considera que o termo "classe" é mais empregado entre os marxistas, mas muitas vezes ele usa o termo "classe" ou "lugar social" como sinônimos.

22 MASSEY, Anne. Hollywood beyond the screen: design and material culture. Oxford; New York: Berg, 2000.
} 
também objetos desta ação social, sofrendo assim os resultados desta atuação, isto é, os agentes sociais são ao mesmo tempo sujeitos e objetos das ações sociais praticadas por eles. Por exemplo, a mesma pessoa que projeta ou propõe o uso dos óculos Manhattan (os agentes da produção), como exemplos de elegância, os usa também. Assim, as relações de força promovidas pelos agentes e as instituições, que lutam entre si no interior do campo para a legitimação desse ou daquele arbitrário cultural, organizam-no e geram a sua estrutura interna, isto é, os seus códigos de referência, os valores as serem respeitados.

Outros importantes agentes do campo são os agentes de circulação, os quais se ocupam de instituir as instâncias que operam depois que os agentes de produção inventam ou criam os óculos, por exemplo. Eles operam na consagração e legitimação destes objetos. Quem afirma que o objeto cenográfico de um filme de Hollywood deve e, acima de tudo, pode estar à venda por um determinado, e geralmente altíssimo, preço em um leilão ou loja? Aliás, quem decide se os óculos modelo " $x$ " ou " $y$ " é elegante ou não? Por que Hollywood é referência mundial de filmes tidos como bons para a maioria do público? Para Bourdieu, são os agentes de legitimação ou consagração que operam na circulação, isto é, na definição disso que é um bom filme em Hollywood e em toda a América e também aquilo que é elegante ou não. $O$ campo é uma convenção social e um processo de diferenciação também social, baseado em valores estabelecidos pelos pares, fundado por regras e consolidado por hierarquias. Logo, quase todas, senão a totalidade das concepções veiculadas em nossa cultura, têm como referência significados que emergem dessas relações construídas pelo campo. É ele quem dá o papel desempenhado pelos filmes na formação das pessoas em sociedades audiovisuais tal como é a nossa. Destarte, se você quiser parecer elegante, use os óculos iguais aos de Holly Golightly.

Faz-se interessante mencionar ainda, que em uma passagem do livro Design for the real world ${ }^{23}$, Victor Papanek (1973, p. 67) mencionou que em meados dos anos trinta a imagem americana no exterior era frequentemente criada pelos filmes. 0 mundo do "faz de conta" comunicou algo que mudou os espectadores estrangeiros mais direta e subliminarmente que qualquer enredo ou estrelas de cinema. Era a comunicação de um espaço idealizado, um ambiente com móveis estofados e equipado com as mais recentes invenções disponíveis. Paralelamente, Forty (2007, p. 265) em Objetos de desejo descreveu que evidenciou-se na década de 1930 a transformação da estética nos designs objetivando responder à demanda da produção industrial. Os filmes da época eram a glorificação da indústria americana através dos objetos que a celebravam, refletindo os ideais da própria América como pátria.

A nossa "competência" para assistir a um filme não restringe-se ao simples fato de ver o que está na tela, mas está circunscrita no universo social e cultural dos indivíduos, naquilo que Bourdieu chamou de disposição prévia que antecede não só ao filme, mas a isso que entendemos por razão ontológica de nossa existência.

Assim como a prática do design, entendemos que a prática do cinema é compreendida enquanto prática social, pois o significado de um filme depende do contexto ou campo no qual ele foi produzido e no qual ele é assistido. É preciso que exista uma atmosfera apropriada para que ele exista enquanto forma de

23 PAPANEK, Victor. Design for the real world. New York: Batam Books, 1973. 
representação social. Neste sentido, os filmes apresentam variadas convenções e padrões sociais na tentativa de fazer gerar algum significado para o público.

A partir daí, pensamos na produção de significados gerados nas trocas simbólicas e acreditamos que o estudo do design de produção também é capaz de evidenciar tais significados. Empregando as noções de Bourdieu, compreendemos que os objetos cenográficos passaram a participar da prática da produção de trocas simbólicas e, desse modo, tornaram-se eles mesmos produtores de códigos simbólicos de consumo. Os objetos cênicos introduzidos nos filmes passam a ser, além de uma produção cultural e simbólica, uma mercadoria para ser comercializada financeiramente. Assim, deparamo-nos com questões, tais como: por qual motivo um objeto cênico passa a ser alvo de consumo de determinados grupos sociais? De que forma certos objetos produzem significados simbólicos, tornando-se símbolos de distinção entre as camadas sociais?

A importância do consumo é fundamental para o desenvolvimento do capitalismo, necessitando que sejam criadas novas estratégias para obtenção de margens de lucro cada vez maiores e, mesmo que não possa ser efetivamente exercido, o mesmo está presente nas crenças e desejos existentes nas sociedades. 0 consumo é parte constituinte da cultura contemporânea, estabelecendo-se como uma prática bastante incentivada pelo sistema capitalista, através da qual os diversos grupos sócio-culturais relacionam-se entre si possuindo ou desejando possuir determinados produtos que atuam como elementos de disputa e distinção.

Relatou Bourdieu (1983, p. 80) que "desde que a história do indivíduo nunca é mais do que uma certa especificação da história coletiva de seu grupo ou de sua classe", é possível observar nos sistemas de disposições de cada indivíduo modalidades estruturais do habitus relativo a um grupo específico pertencente a uma classe social. Sob esse ponto de vista, então o habitus é o gerador do gosto da classe social e é compreendido como o causador de todas as práticas. Dessa forma, existiria um gosto possível para cada posição social e tal gosto não está livre das imposições da vida em sociedade.

Bourdieu (1983, p. 84) expôs que os grupos sociais tendem a investir em tudo o que os contrasta em relação aos outros grupos, desejando exprimir uma identidade particular, "quer dizer, sua diferença" completa.

Em inúmeros casos, é fácil identificar grupos sócio-culturais, pois os mesmos se diferenciam pelo desejo de possuir determinados objetos em função de seus valores simbólicos predominantes considerados representações de inclusão social em um determinado grupo e status para os demais.

Observa-se que os grupos sócio-culturais que exercem as mesmas práticas de consumo reproduzem permanentemente um mesmo comportamento, o qual baseiase em representações características daquele determinado conjunto de membros. Simultaneamente, as mercadorias operam não como elementos funcionais, mas de distinção social, acarretando no desejo das classes sociais de possuir aquilo que tem o poder de destacá-las de alguma forma e retornamos ao caso do consumidor do tênis Nike Air Mag do filme De volta para o futuro II, por exemplo. Assim sendo, a irracionalidade de apropriação dos símbolos inseridos em diferenciados grupos sócioculturais estabelece-se através do desejo de tornar-se elemento padrão incluído em um conjunto através da aquisição do mesmo objeto considerado simbolicamente superior. 
Bourdieu (1983, p. 83-84) referiu-se ao conjunto das "propriedades", termo utilizado no duplo sentido, de que se ladeiam os indivíduos ou grupos - "casas, móveis, quadros, livros, automóveis, alcoóis, cigarros, perfumes, roupas" - e nas práticas em que evidencia-se sua distinção - "esportes, jogos, distrações culturais" - pois estão inseridas no habitus. $\mathrm{O}$ gosto, preferência à apropriação seja material e/ou simbólica de uma categoria de objetos em particular, é a fórmula geradora que encontra-se no princípio do estilo de vida. O estilo de vida traduz-se em um conjunto de preferências distintivas que expressam-se, entre outros, na mobília e nas vestimentas.

Quanto mais raro, mais "novo" e/ou mais luxuoso, mais distintivo é o objeto. Consumir revela-se como um processo de mediação de relações sociais e revelador de distinções sociais, o qual produz valores simbólicos através dos objetos, incluindo os cênicos de filmes hollywoodianos.

\section{CONCLUSÃO}

Prolongando as noções de Bourdieu, entendemos, humildemente, que o design está expresso nos objetos projetados pelos designers, mas o que produz tal processo está inculcado através do habitus do contexto social no qual tais designers encontramse inseridos e o mesmo acontece com os designers de produção e os objetos cênicos dos filmes de produções hollywoodianas. Dessa forma, parece-nos ser um desacerto acreditar que o valor simbólico está no objeto. Estaria então no recôndito de cada espectador individualmente, na subjetividade do consumidor? Concluímos que os significados estão nas estruturas sociais e são reproduzidos pelos agentes sociais nelas inseridos. A presença dos objetos cênicos nos leilões e nas lojas ratificam que o processo do design está no contexto social onde ele aparece.

Os leilões e as lojas são a legitimação da indústria cinematográfica hollywoodiana exaltada através dos objetos cênicos consagrados também pelos próprios agentes do Campo do Cinema. E por que não afirmar que também pelo Campo do Design?

Os objetos cênicos refletem a soberania hollywoodiana cinematográfica como um símbolo de poder, simbolizando também ideologicamente a nacionalidade patriótica e o orgulho de possuir algo que represente a América idealizada dos filmes hollywoodianos. Hollywood é consagrada pelos americanos que são influenciados por essa grandiosa indústria e por seus agentes de circulação que lá trabalham. Hollywood é ao mesmo tempo a causa e o efeito, estruturado e estruturante, da representação social da nação americana como soberana e a afirmação desta estrutura social.

O habitus da estrutura social americana, tanto coletivo como individual, é constituído também deste patriotismo exacerbado, deste sentimento já imposto através de um processo de inculcação de pertencer a esta grande nação influente e tal habitus se reafirma a todo instante através de cada objeto exposto nos leilões e nas lojas e nos próprios filmes de Hollywood. Os objetos cenográficos são intensamente comercializados, pois é constatada a "necessidade" do indivíduo de fazer parte de alguma coisa, mesmo que seja pela obrigação de se sentir adequado a uma estrutura social, de participar das trocas simbólicas que as outras pessoas estão participando, ou seja, consumindo. 
A latinha de óleo da imagem abaixo pertencente ao personagem Homem de Lata do filme $O$ Mágico de $\mathrm{Oz}^{24}$ assinada pelo ator, cujo valor na loja Antiquities era de dois mil quatrocentos e noventa e cinco dólares quando o site da loja foi acessado em 20 de abril de 2106, já não encontra-se mais à venda. O segundo acesso ao site foi realizado no dia 26 de abril de 2016, menos de uma semana depois.

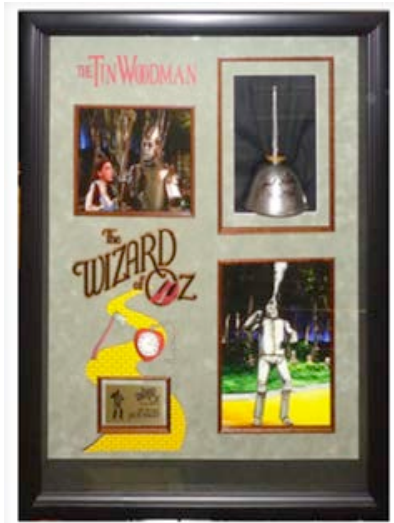

Wizard Of Oz Signed Jack Haley Oil Can

\section{$\$ 2,495.00$}

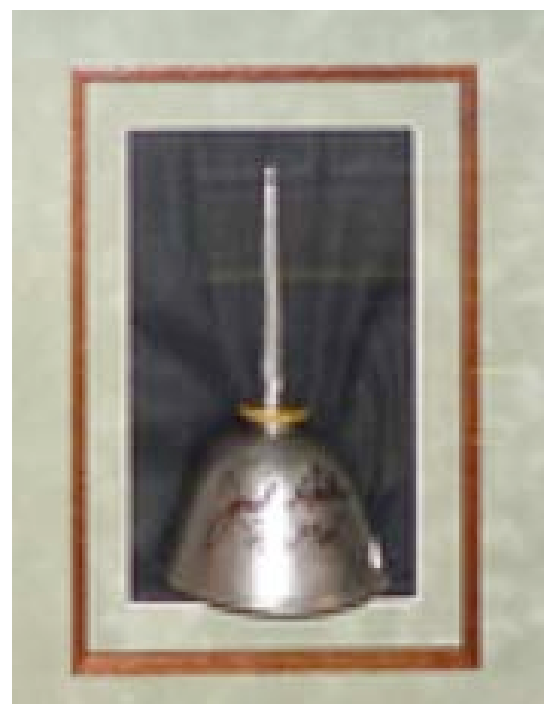

Figura 2 - Lata de óleo do Homem de Lata de $\mathrm{O}$ Mágico de $\mathrm{Oz}$

Fonte: retirada do site da loja Antiquities quando acessado em 20/04/2016.

\section{REFERÊNCIAS}

BOMFIM, Gustavo A. Coordenadas cronológicas e cosmológicas como espaço das transformações formais. In: COUTO, Rita M. de Souza; OLIVEIRA, Alfredo J. de; FARBIARZ, Jaqueline Lima; NOVAES, Luiza (org.). Formas do design: por uma metodologia interdisciplinar. Rio de Janeiro: Rio Books, 2014.

BOURDIEU, Pierre. A sociologia de Pierre Bourdieu. Organização: Renato Ortiz. Tradução: Paula Montero e Alícia Auzmendi. São Paulo: Ática, 1983.

FORTY, Adrian. Objetos de desejo. Tradução: Pedro Maia Soares. Cameron Books, 1986. São Paulo: Cosac Naify, 2007.

HAMBURGER, Vera. Arte em cena: a direção de arte no cinema brasileiro. São Paulo: Senac-Sesc, 2014.

LOBRUTTO, Vincent. The filmmaker's guide to production design. New York: Allworth Press, 2002.

MASSEY, Anne. Hollywood beyond the screen: design and material culture. Oxford; New York: Berg, 2000.

PAPANEK, Victor. Design for the real world. New York: Batam Books, 1973.

24 O Mágico de Oz. Titulo original: The Wizard of Oz. Estados Unidos, 1939. Cor. 101 min. Direção: Victor Fleming. 
PRESTON, Ward. What an Art Director does: an introduction to Motion Picture Production Design. Los Angeles, Silman-James Press, 1994. 